\title{
ANÁLISE DE JOGOS DIGITAIS: aspectos da linguagem visual relacionados às funções interativas em dispositivos portáteis
}

\author{
Bruno Serviliano S. Farias \\ Universidade Federal do Maranhão \\ brunoserviliano@gmail.com \\ Mário Meireles Teixeira \\ Universidade Federal do Maranhão \\ mario@deinf.ufma.br
}

\begin{abstract}
Resumo: Apresenta-se neste trabalho o resultado de uma pesquisa que analisou jogos digitais em dispositivos de interação portátil, abrangendo aspectos da linguagem gráfica e elementos interativos para estruturação da informação. Esta pesquisa possui caráter descritivo-analítico, com abordagem quantitativa. $O$ estudo descritivo registrou e catalogou interfaces sob a ótica de três funções: navegação, instrução e comunicação interativa. Para tal, foi desenvolvida uma ferramenta de apoio visando guiar a observação bem como facilitar a análise. $O$ estudo analítico demonstrou a incidência crítica de cada elemento e estratégia confrontando com princípios interativos. Os resultados mostraram a relação entre princípios e funções interativas além de fornecer dados significativos no desenvolvimento de sistemas digitais. Conclui-se que a análise de jogos é fundamental para se compreender como ocorre a estruturação da informação, bem como quais são as formas de apresentação mais adequadas para cada função interativa.
\end{abstract}

Palavras-chave: Análise de Jogos. Apresentação da Informação. Princípios Interativos.

\section{INTRODUÇÃO}

A avaliação de sistemas interativos é uma atividade fundamental para o desenvolvimento de interfaces digitais em um contexto de popularização desses artefatos. No entanto, há carências de pesquisas sobre interação em dispositivos portáteis, principalmente com enfoque em design de informação e design de interação. Autores como Rogers et al (2013), Cybis (2010), Barbosa e Silva (2010), apresentam pesquisas focados em sistemas digitais gerais ou sistemas já estabelecidos como computadores ou páginas de internet. Neil (2012), por outro lado, apresenta várias estratégias para dispositivos móveis e portáteis, embora ela parta de comentários de usuários e de padrões já consagrados e não destaque as características e a estruturação de informação nesses artefatos. 
Nesse sentido, pesquisas que avaliam sistemas e usuários permitem conhecer estes cenários e garantir o desenvolvimento de boas práticas no design de interfaces de sistemas digitais. Pesquisas com usuário são ricas em detalhes, no entanto, demandam tempo e recursos.

A análise proposta nesta pesquisa destina-se a designers e programadores de sistemas digitais, que têm a função de desenvolver sistemas e interfaces interativos, que necessitam de informações detalhadas, as quais muitas vezes não dispõem de tempo ou recursos para avaliá-los com o usuário.

Os tipos de dispositivos escolhidos foram os artefatos portáteis, pelo fato de serem relativamente novos comparados a outros dispositivos como os fixos (computadores de mesa, por exemplo). Os sistemas digitais escolhidos foram os jogos digitais, por apresentarem diversas formas de interação com interfaces ricas em elementos gráficos e diversas estratégias de estruturação de informação.

O objetivo principal do estudo é conhecer as principais formas de estruturação da informação e relacionar seus princípios à função interativa. A pesquisa justifica-se por permitir ao avaliador realizar diversas reflexões sobre o uso e emprego de componentes gráficos e interativos bem como sinalizar eventuais problemas de ordem prática. É nesse contexto que a presente pesquisa posiciona-se, em gerar informações prévias que sirvam de reflexão para o início do projeto de sistemas interativos.

\section{FUNÇÕES INTERATIVAS}

Com o propósito de analisar as funções de sistemas interativos adotou-se neste trabalho os estudos de Pressman (1995), Xavier (2010) e Cybis (2010) para definir quais funções seriam estudas e observadas. Baseado nesses autores, foram adaptadas três funções interativas. São elas: navegação, instrução e comunicação interativa.

Cada função relaciona-se ao grau de envolvimento do usuário no jogo com a finalidade de gerenciar as expectativas e conduzir adequadamente o jogador no sistema interativo. Para tal, buscou-se definir conceitos e estratégias de estruturação da informação. A seguir será apresentada uma tabela resumindo as funções e estratégias:

\section{Tabela 1: Funções e estratégias de estruturação da informação}

\section{Definição}

\section{Navegação}

É o meio pelo qual os usuários se deslocam, se preparam e fazem os ajustes antes de realizar a atividade fim do jogo.

\section{Instrução}

É o processo que possui finalidade prática de tornar os elementos visuais familiares. 0 objetivo é fornecer aos usuários condições para definir planos de ação durante o jogo.

\section{Estratégias}

Deslocamento: quando os elementos indicam movimento para apresentar várias opções em páginas diferentes, subdivididas em navegação por carrossel e mapa.

Relação Gráfica: quando os elementos são todos apresentados na interface sem transbordar a informação para fora da tela. Pode ser dividida em: navegação por menu lista, abas e galeria.

\section{Com relação ao tempo:}

o Tempo do conteúdo - tempo natural do evento relatado.

o Tempo do discurso - sujeito às características da forma através da qual é apresentado.

Com relação à apresentação:

o Destacada - ressalta do ambiente virtual pausando a interação. 
o Contextualizada - ocorre no mesmo ambiente do jogo sem perder o controle com os elementos interativos.

o Transicional - ocorre entre as partidas.

o Menu - a instrução está acessível pelo menu. Com relação ao reconhecimento:

o Usuário - o sistema reconhece vários usuários.

o Dispositivo - o sistema reconhece apenas o dispositivo.

\section{Comunicação Interativa}

Segundo Cybis et al (2010, p. 257), são formas ativas de comunicação em que o usuário aciona os recursos interativos e obtém respostas distintas e imediatas. Para efeito de análise foram definidas quatro formas de comunicação interativa: menu, feeedback, restrição e controle.
Menu - é o elemento de diálogo entre o usuário e o sistema que permite o usuário acessar aspectos do jogo, como volume, acesso à instrução, avançar ou voltar a uma fase etc.

o Apresentação - lista ou conceitual. A lista ocorre quando se evidencia uma estrutura ortogonal dos elementos. Conceitual quanto se evidencia o próprio conceito visual do jogo.

o Relação com o jogo - opaco ou translúcido. Opaco quando se valoriza apenas o menu, ocultando o jogo. Translúcido quanto mesmo acessando o menu ainda pode-se observar o jogo.

Feedback - é o princípio relacionado ao conceito de visibilidade. A finalidade é informar a mudança no estado do jogo ou instruir a respeito de algum elemento ou situação.

o Apresentação - lista ou conceitual. A lista ocorre quando se evidencia a estrutura ortogonal dos elementos. Conceitual quanto se evidencia o próprio conceito visual do jogo.

o Momento - durante o jogo ou entre as fases (antes e/ou depois).

Restrição - refere-se ao princípio que limita as ações dos usuários visando orientá-los a tomar a decisão correta, ou no caso dos jogos, elevar o nível de dificuldade. As estratégias serão definidas pela observação em jogos digitais.

Controle - refere-se ao princípio de como as ações humanas estão conectas às ações do sistema. Baseado na literatura e na observação identificam-se dois tipos de estratégias de controle em jogos digitais em dispositivos portáteis:

o Controle explícito pictórico - são áreas visualmente predeterminadas que permitem o controle durante a ação principal do jogo.

o Controle implícito gestual - são gestos predeterminados que permitem o controle durante a ação principal do jogo.

Fonte: Elaborada pelo autor a partir de dados obtidos através da pesquisa, 2014.

\section{ANÁLISE DE JOGOS}

O presente estudo utiliza técnicas de inspeção para analisar 57 jogos digitais. A natureza da ferramenta de análise de jogos digitais não envolve o usuário mas sistemas interativos desenvolvidos permitindo que vários jogos sejam comparados. A comparação gerou uma média na qual serve como guia para definir padrões para a categoria do jogo 
pretendido e assim apontar aquele que seja significativo para o projeto.

A inspeção utiliza várias técnicas padronizadas de coleta de dados, tais como ferramenta de apoio (ferramenta de análise) e a observação sistemática (registro das telas). Antes da análise, a pesquisa selecionou os jogos, categorizou, registrou as interfaces de cada jogo em cada momento interativo e catalogou cada interface de acordo com as funções previamente estabelecidas.

Depois, foram observadas as funções, os elementos gráficos e estratégias utilizados na ferramenta de apoio. Para os elementos gráficos foi considerada a classificação de Twyman (1982, apud PETTERSSON, 2002, p. 65) que categoriza os elementos gráficos em pictóricos, verbais e esquemáticos. A repetição de um determinado elemento em várias telas garantirá que determinada categoria do elemento não seja omitida. No entanto, o objetivo não é somar a quantidade de vezes que um determinado item aparecer e sim se determinada categoria está presente.

A tabulação dos dados observou a ocorrência das categorias e o cruzamento dos dados, mediante a análise estatística. A indicação da incidência de cada elemento e estratégias é guiada pela ferramenta de análise de jogos, no qual constam os elementos e estratégias das funções.

Os jogos foram selecionados pela App Store, loja virtual da Apple. O critério de escolha dos jogos foi baseado na popularidade em cada categoria. Para manter a imparcialidade na seleção foram escolhidos 57 jogos em quatro categorias, que são: ação e exploração, aventura, RPG e estratégia, esportivos e simulação. Nesse sentido pode-se verificar se há uma categoria que emprega mais elementos gráficos ou mais estratégias de instrução, verificar também as diferenças e as semelhanças.

Diante desse detalhamento da pesquisa, o que será apresentado é a análise rudimentar, com as ocorrências e a análise cruzada que refere-se ao cruzamento desses dados através de funções estatísticas. Através da análise cruzada pode-se relacionar os princípios interativos das funções interativas.

\subsection{Resultados da Pesquisa}

A tabela 2 a seguir apresenta os resultados da tabulação de 57 jogos digitais.

Tabela 2: Dados rudimentares

\begin{tabular}{|c|c|c|c|c|c|c|c|}
\hline \multirow[b]{2}{*}{ Função } & & & & & Jcorrência & & \\
\hline & \multicolumn{2}{|c|}{ Elementos/Estratégias } & Aventura & Ação & Estratégia & Esportivo & Total \\
\hline \multirow{8}{*}{ 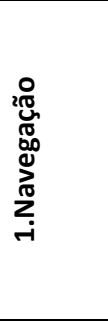 } & \multirow{3}{*}{$\begin{array}{l}\text { Elemento } \\
\text { Gráfico }\end{array}$} & Pictórico & 10 & 21 & 12 & 10 & 53 \\
\hline & & Verbal & 10 & 23 & 11 & 11 & 55 \\
\hline & & Esquemático & 8 & 20 & 10 & 9 & 47 \\
\hline & \multirow{3}{*}{$\begin{array}{l}\text { Relação } \\
\text { Gráfica }\end{array}$} & Lista & 7 & 14 & 3 & 5 & 29 \\
\hline & & Abas & 5 & 6 & 7 & 2 & 20 \\
\hline & & Galeria & 5 & 11 & 11 & 6 & 33 \\
\hline & \multirow{2}{*}{$\begin{array}{l}\text { Deslocamento } \\
\text { virtual }\end{array}$} & Carrossel & 8 & 13 & 10 & 7 & 38 \\
\hline & & Mapa & 3 & 2 & 2 & 1 & 8 \\
\hline \multirow{9}{*}{ 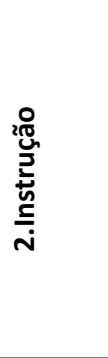 } & \multirow{3}{*}{$\begin{array}{l}\text { Elemento } \\
\text { Gráfico }\end{array}$} & Pictórico & 3 & 14 & 2 & 7 & 26 \\
\hline & & Verbal & 9 & 15 & 10 & 8 & 42 \\
\hline & & Esquemático & 5 & 12 & 11 & 6 & 34 \\
\hline & \multirow{4}{*}{$\begin{array}{l}\text { Momento da } \\
\text { Apresentação }\end{array}$} & Destacada & 3 & 7 & 5 & 5 & 20 \\
\hline & & Contextualizada & 8 & 12 & 8 & 5 & 33 \\
\hline & & Transicional & 4 & 2 & 1 & 3 & 10 \\
\hline & & Menu & 2 & 5 & 5 & 1 & 13 \\
\hline & \multirow{2}{*}{$\begin{array}{l}\text { Estilização do } \\
\text { tempo }\end{array}$} & Tempo do conteúdo & 5 & 11 & 6 & 3 & 25 \\
\hline & & Tempo do discurso & 6 & 9 & 7 & 7 & 29 \\
\hline
\end{tabular}




\begin{tabular}{|c|c|c|c|c|c|c|c|}
\hline & \multirow{2}{*}{$\begin{array}{l}\text { Reconheci- } \\
\text { mento }\end{array}$} & Usuário & 0 & 0 & 2 & 1 & 3 \\
\hline & & Dispositivo & 10 & 24 & 10 & 10 & 54 \\
\hline Função & \multicolumn{2}{|c|}{ Elementos/Estratégias } & Aventura & Ação & Estratégia & Esportivo & Total \\
\hline \multirow{7}{*}{$\underset{i}{\sum_{i}^{\vec{d}}}$} & \multirow{3}{*}{$\begin{array}{l}\text { Elemento } \\
\text { Gráfico }\end{array}$} & Pictórico & 7 & 13 & 9 & 4 & 33 \\
\hline & & Verbal & 10 & 21 & 11 & 8 & 50 \\
\hline & & Esquemático & 6 & 9 & 7 & 6 & 28 \\
\hline & \multirow[t]{2}{*}{ Apresentação } & Lista & 10 & 22 & 11 & 9 & 52 \\
\hline & & Conceitual & 1 & 1 & 1 & 0 & 3 \\
\hline & \multirow{2}{*}{$\begin{array}{l}\text { Relação com o } \\
\text { jogo }\end{array}$} & Opaco & 3 & 9 & 6 & 3 & 21 \\
\hline & & Translúcido & 7 & 14 & 6 & 7 & 34 \\
\hline \multirow{8}{*}{ 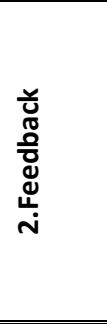 } & \multirow{3}{*}{$\begin{array}{l}\text { Elemento } \\
\text { Gráfico }\end{array}$} & Pictórico & 7 & 18 & 9 & 6 & 40 \\
\hline & & Verbal & 10 & 24 & 10 & 11 & 55 \\
\hline & & Esquemática & 4 & 10 & 5 & 9 & 28 \\
\hline & \multirow[t]{2}{*}{ Apresentação } & Lista & 10 & 24 & 12 & 11 & 57 \\
\hline & & Conceitual & 0 & 1 & 0 & 0 & 1 \\
\hline & \multirow[t]{3}{*}{ Momento } & Antes das fases & 7 & 12 & 9 & 7 & 35 \\
\hline & & Durante o jogo & 10 & 20 & 12 & 10 & 52 \\
\hline & & Depois das fases & 9 & 22 & 12 & 10 & 53 \\
\hline \multirow{2}{*}{3.} & \multirow{2}{*}{ estrição } & Instruir & 5 & 6 & 1 & 6 & 14 \\
\hline & & Premiar & 9 & 10 & 21 & 11 & 52 \\
\hline \multirow{5}{*}{ 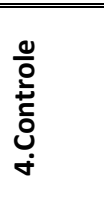 } & Visual & & 4 & 5 & 8 & 0 & 18 \\
\hline & Gestual & & 6 & 7 & 19 & 12 & 47 \\
\hline & \multirow{3}{*}{$\begin{array}{l}\text { Elemento } \\
\text { Gráfico }\end{array}$} & Pictórico & 4 & 5 & 0 & 4 & 13 \\
\hline & & Verbal & 0 & 2 & 0 & 2 & 4 \\
\hline & & Esquemático & 1 & 4 & 0 & 1 & 6 \\
\hline
\end{tabular}

Fonte: Elaborada pelo autor a partir de dados obtidos através da pesquisa, 2014.

Os dados da tabulação foram cruzados através de análises estatísticas a fim de encontrar outros resultados. A escala, apresentada na tabela 3 a seguir, é a unidade de equiparação, variando de $0-1$, referente à relação entre a média aritmética de cada elemento ou estratégia pelo número total de jogos analisados. A escala, nesse sentido, informa o grau de redundância dos elementos gráficos e a quantidade de estratégias relativas utilizadas no total da amostra analisada. O resultado analisado por função encontra-se na sequência.

Tabela 3: Análise das Funções

\section{Função Navegação}

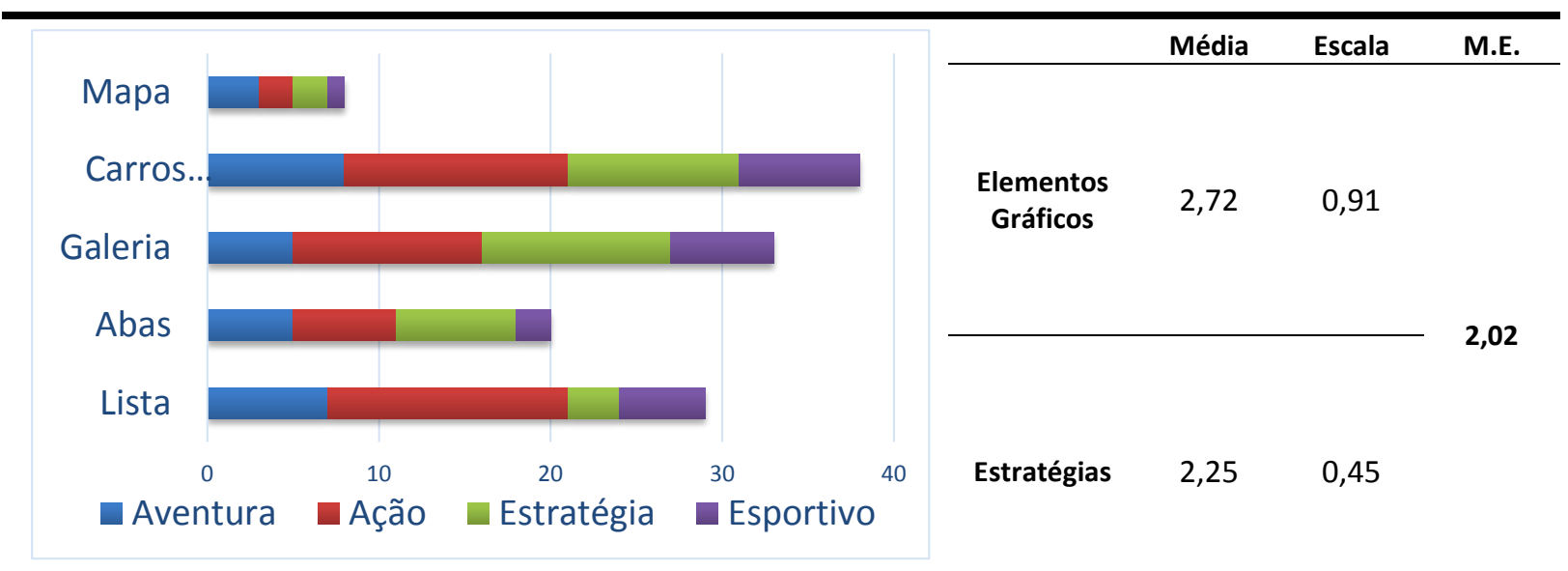

\section{Análise dos resultados:}

A estratégia por Carrossel, destaque dessa função, permite apresentar várias opções de modo a não gerar uma sobrecarga cognitiva, na medida em que as informações são agrupadas e apresenta- 
das separadamente em telas diferentes, sendo acessível através do deslocamento da informação. Poder-se-ia afirmar que a navegação teria uma relação com o princípio da redução da carga cognitiva, mas a segunda estratégia em destaque não preza por esse princípio. A galeria permite a apresentação de várias opções na interface, privilegiando a visibilidade da informação. Então não se pode afirmar que a redução da carga cognitiva ou a visibilidade das informações são princípios fundamentais a essa função, apenas uma escolha do projeto. Além disso, tem-se o fato de que essa função apresenta a maior quantidade de elementos gráficos, tanto em números absolutos quanto na média, é possível que essas funções tenham um forte imperativo informativo.

Padovani e Moura (2008) citam que a memória de curta duração é bastante exigida na função da navegação, uma vez que essa tarefa exige a apreensão de novos conteúdos e a atividade da navegação em si. Desta forma, pode-se relacionar a função da navegação com a memória, o que exige um considerado esforço cognitivo, ainda mais se considerarmos que usuários de dispositivos cognitivos são intervenientes e precisam de indicação quando retornar ao sistema.

Pode-se confirmar essa relação entre a navegação e memória verificando a média dos elementos gráficos por jogo, 2,72, próximo da máxima que é 3, para esses elementos e a média de elementos gráficos por estratégia (M.E.) é de mais de dois elementos $(2,25)$, reforçando que esta função utiliza princípio da redundância da informação.

Princípio: Redundância da informação.

\section{Função Instrução}

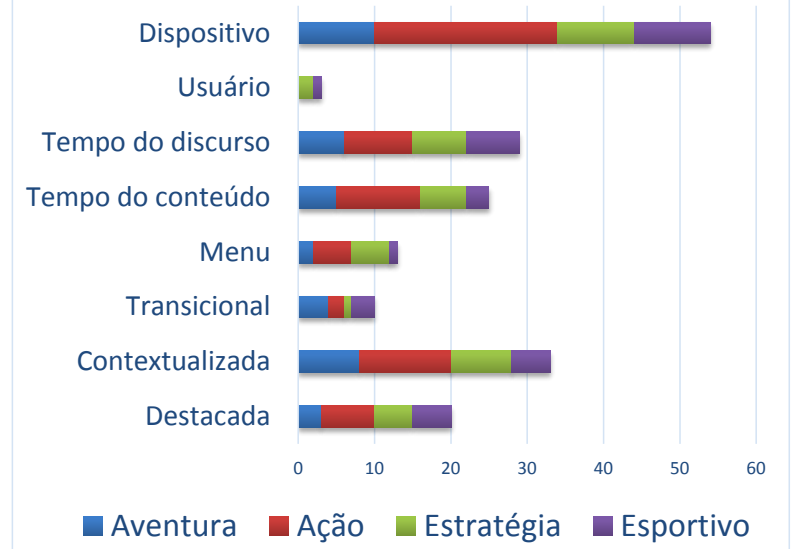

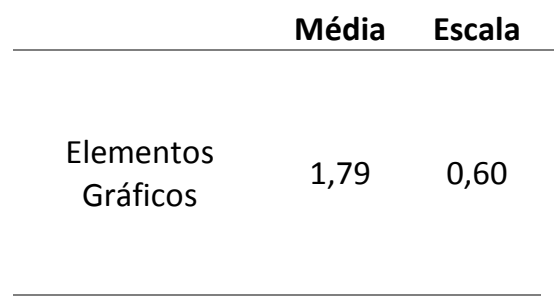

1,45

Estratégias $\quad 3,28 \quad 0,41$

\section{Análise dos resultados:}

A estratégia de reconhecimento por dispositivo pode indicar que os fabricantes de jogos veem os dispositivos portáteis como artefatos pessoais e nessa perspectiva não teriam problemas ao reconhecer a experiência dos usuários.

A estratégia de apresentação contextualizada permite uma aproximação da função instruir com a familiaridade dos jogos, na medida em que utiliza a mesma situação, com os mesmos elementos e disposições espaciais, facilitando o reconhecimento e o aprendizado. Essa relação espacial, onde ocorre a estrutura lúdica do jogo e a instrução, pode indicar uma maior facilidade no processo de aprendizado. Mesmo a estratégia de instrução destacada não se desvincula completamente do ambiente lúdico, muitos jogos utilizam uma estrutura transparente ou parcialmente opaca.

Padovani e Moura (2008) alertaram da relação memória de longa duração e a repetição. A instrução é uma função relacionada ao aprendizado e ao controle. Sabe-se que as funções interativas apresentadas na instrução serão repetidas ao longo dos jogos. Nesse sentido, pode-se relacionar a instrução ao processo de memória de longa duração. Essa relação é mediada pela repetição dos controles interativos exigindo pouco esforço cognitivo devido ao processo de internalização da aprendizagem. É nessa função que o usuário inicia os comandos que irá repetir ao longo do jogo. É possível perceber o baixo esforço cognitivo na relação entre as escalas (M.E) de 1,45 , pois indica que é necessário um pouco mais de um tipo de elemento para instruir.

Princípio: Contiguidade espacial-espacial e redução da sobrecarga visual. 


\section{Processo Comunicativo - Menu}

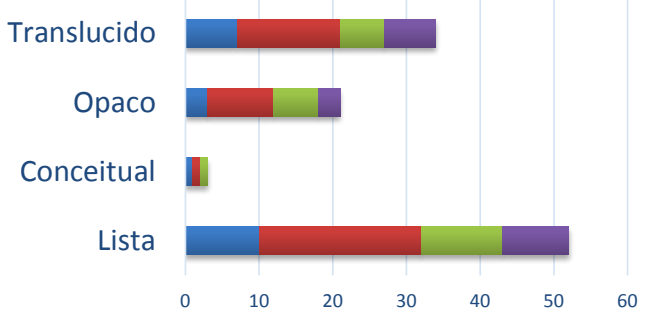

aventura $\square$ Ação Estratégia Esportivo

\begin{tabular}{cccc} 
& Média & Escala & M.E. \\
\hline $\begin{array}{c}\text { Elementos } \\
\text { Gráficos }\end{array}$ & 1,95 & 0,65 & \\
\hline & & & \\
& & & \\
Estratégias & 1,93 & 0,48 &
\end{tabular}

\section{Análise dos resultados:}

A notoriedade na estratégia de apresentação por lista pode enfatizar a necessidade da simplicidade da estruturação da informação. Como defende Cybis (2010, p. 57) esse processo tem como objetivo minimizar as ações, propiciando acesso rápido às opções de comando mais frequentes. Dessa forma, uma estrutura simples e eficiente seria mais apropriada. A média de 1,35 das relações das escalas reforça a tese da simplicidade. Ao verificar a ocorrência dos elementos gráficos percebe-se uma forte presença dos elementos verbais, presentes quase na totalidade dos jogos e, eventualmente, com um segundo elemento de redundância, pictórico ou esquemático. Ou seja, pouco mais de um tipo de elemento é necessário para essa função.

Princípio: Projeto estético minimalista e modalidade verbal.

\section{Processo Comunicativo - Feedback}

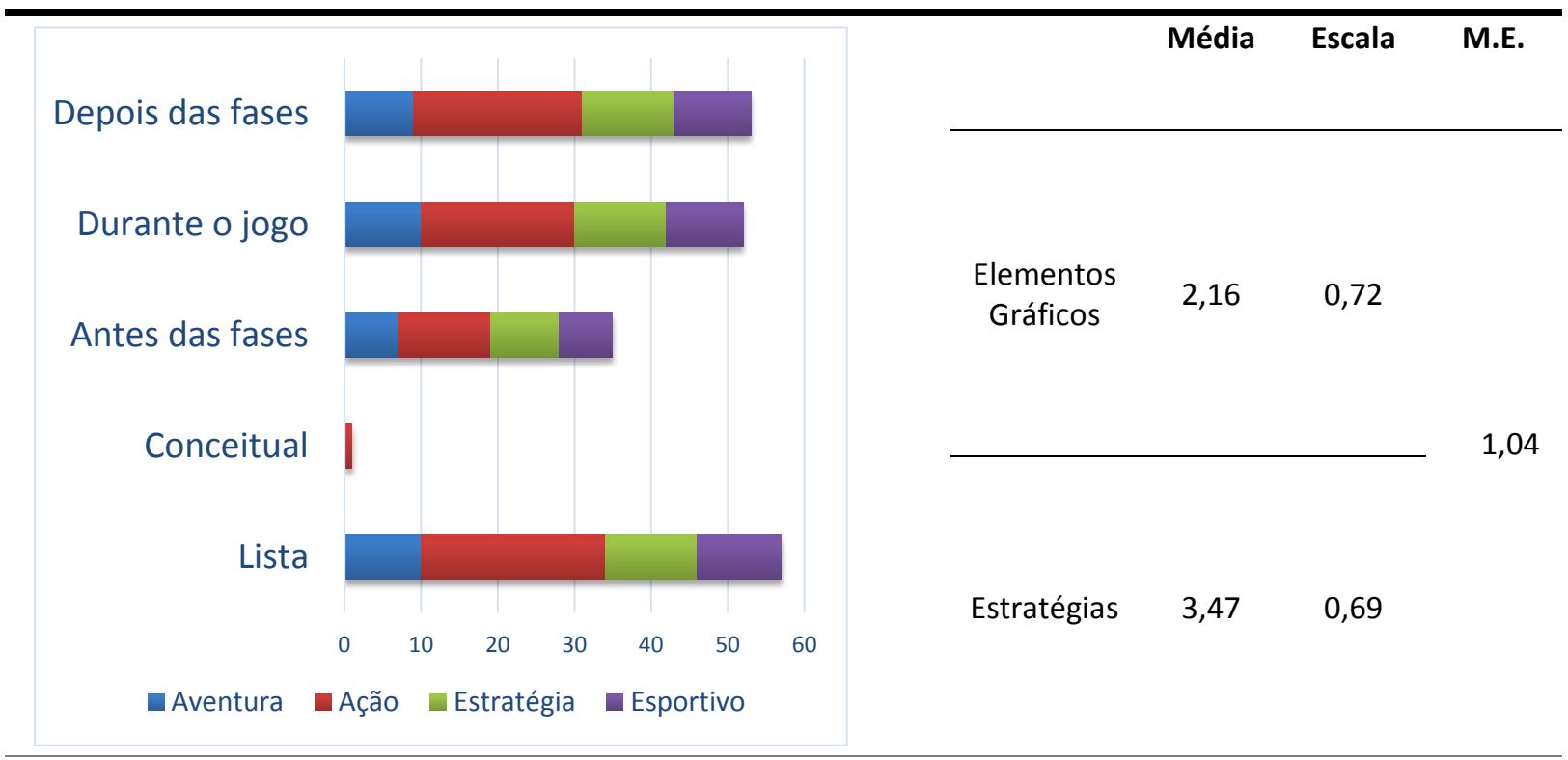

\section{Análise dos resultados:}

O equilíbrio entre os empregos das estratégias e a elevada média de tipos de estratégias por jogo permite concluir que o principal objetivo dessa função é informar, o que coaduna com as ideias de Rogers et al (2013, p. 26) o qual relaciona tal função ao conceito de visibilidade. No entanto, para informar, a função emprega, em média, um pouco mais de dois tipos de elementos por jogo. Interessante notar que apesar disso, essa função utiliza um elemento por estratégia (M.E. 1,04), indicando que embora a função principal do feedback seja informar, ela não gera um esforço cognitivo, apenas o necessário para compreender.

Nesse sentido, é exatamente o que Barbosa e da Silva (2010, p. 274) afirmam quando comentam sobre sistema interativo, pois eles não devem exigir da memória do usuário muitas informações e nem permitir que os usuários procurem informações acerca do estado do sistema. Ou seja, devem 
estar presentes sem gerar esforço cognitivo.

Princípio: Visibilidade do estado do sistema e redução do sobrecarga visual.

\section{Processo Comunicativo - Controle}

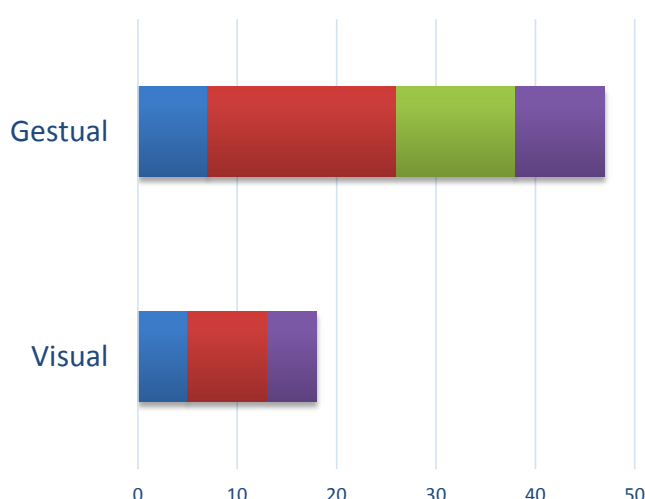

\begin{tabular}{lll} 
& Média & Escala \\
\hline & & \\
Elementos & & \\
Gráficos & 0,40 & 0,13 \\
& & \\
\hline
\end{tabular}

M.E.

- Aventura घAção $\square$ Estratégia $\square$ Esportivo

\section{Análise dos resultados:}

A elevada incidência da estratégia gestual indica a tendência dessa estratégia em dispositivos portáteis. É a única função que não tem como principal elemento gráfico o elemento verbal. Se não há elementos gráficos, apenas gestos para controlar as interações, essa função apresenta um baixo esforço cognitivo, uma vez que está relacionada à instrução, à repetição e tem como referências comandos mais naturais. Desta forma, como não há elementos gráficos, os gestos podem ocorrer em qualquer área da tela, flexibilizando a posição das mãos.

Princípio: Mapeamentos e redução do sobrecarga visual.

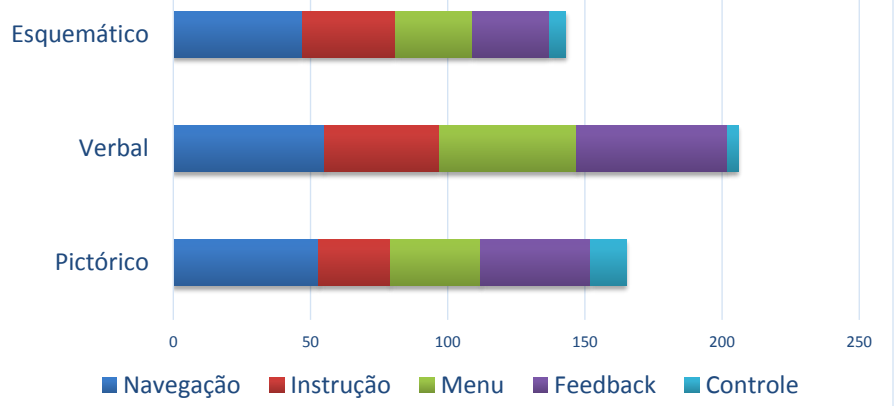

\section{Análise dos resultados:}

A linguagem verbal é o elemento gráfico mais presente nas funções, por isso pode-se inferir que há uma tendência na busca da eficiência no processo de comunicação, o que é inerente a esse elemento. No entanto, a presença dos outros dois elementos em diversas situações reforça a tese da importância da redundância da informação ${ }^{1}$.

Fonte: Elaborada pelo autor a partir de dados obtidos através da pesquisa, 2014.

\subsection{Reflexões e princípios dos jogos digitais}

As relações estipuladas entre os princípios e as funções interativas não existem em um sentindo absoluto. Pode-se considerá-las úteis na medida em que se buscam formas eficientes de diálogos entre sistemas e usuários.

\footnotetext{
${ }^{1}$ Não foi comentada a estratégia da Restrição pelo fato dela não apresentar elementos gráficos e apenas dois tipos de estratégias, tornando a análise mais adequada nos dados rudimentares.
} 
Tabela 4: Reflexões sobre os jogos

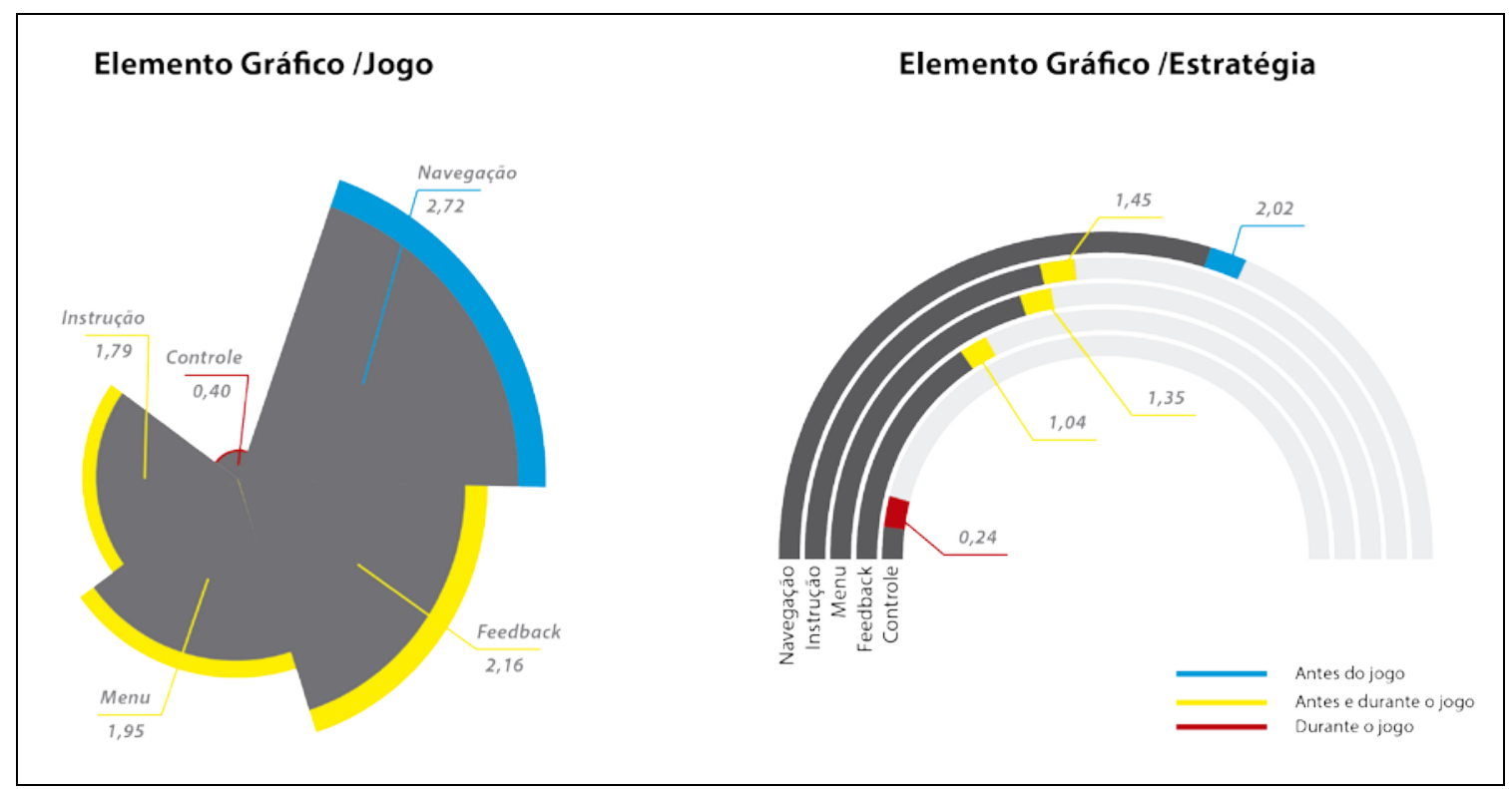

Fonte: Elaborada pelo autor a partir de dados obtidos através da pesquisa, 2014.

Visualizando o panorama geral do resultado da pesquisa, percebe-se que a navegação, que ocorre antes da ação lúdica do jogo, emprega mais tipos de elementos gráficos do que as funções intermediárias, que ocorrem antes e durante a ação lúdica, são elas a instrução, menu e feedback. O controle, que ocorre estritamente durante a ação lúdica, emprega menos tipos de elementos gráficos do que as outras funções. Nesse sentido, a função mais afastada da função lúdica (assinalado na cor azul no gráfico) tem como princípio a redundância da informação. A função que mais se envolve com a ação lúdica (assinalado em vermelho no gráfico) tem na simplicidade estética uma estrutura minimalista da informação apoiada pela assimilação da repetição. Essas polaridades de princípios expõem o dilema de projetos de interfaces: a facilidade de uso e complexidade de funções.

Como o objetivo de sistemas lúdicos é o ato de jogar, as funções mais distantes desse ato precisariam garantir a sobrevivência do sistema, por isso alimenta o usuário com informações para chamar atenção. Na outra ponta, quando o usuário está entretido com a diversão digital as funções interativas garantem a nudez lúdica pura sem distrações. Nesse sentido, os elementos gráficos empregados nas funções interativas tem a função de sinalizar os possíveis caminhos, pavimentando a direção do usuário. Uma vez orientado, o jogador possui informações suficientes para prosseguir seu caminho de entretenimento com o mínimo de distração.

Para determinar as escolhas projetuais de sistemas interativos é necessário refletir sobre questões como:

- Redundância informativa - Quais são os mínimos e máximos de elementos expostos pela interface que garantam a eficácia dos sistemas em cada função?

- Processo de instrução - O quanto familiar o sistema deve ser para propiciar o reconhecimento?

- Visibilidade, feedback e acesso - Quais funções devem ser visíveis e quais devem ser ocultadas?

- Estruturas simples, funções complexas e estratégias de organização Qual o modelo sintático de organização espacial e suas estratégias de 
apresentação?

Trabalhar com estruturas simples facilita a tomada de decisão do usuário, pois evidencia quais opções são mais relevantes. Funções como o menu e feedback, que estão na parte intermediária (amarelo) do gráfico na Tabela 4, ocorrem de modo alternado aos estímulos visuais e sonoros dos jogos. A concorrência entre as funções interativas e a atividade lúdica dos jogos pode gerar uma sobrecarga cognitiva. Nesse sentido, funções com estéticas minimalistas são bastante usadas quando estão em contato com os sistemas lúdicos dos jogos. Além disso, segundo Maeda (2007, p. 23), a simplicidade gera economia de tempo. Considerando o perfil dos usuários móveis, essa economia é necessária.

Pode-se perceber que vários jogos tentam controlar a expectativa e o tempo de espera do jogador utilizando várias estratégias. Uma delas é simplificar a estrutura, a outra ocorre quando a espera é inevitável, como, por exemplo, o processamento do sistema. No caso da espera do processamento muitos jogos tentam tornar esse momento mais tolerável, instruindo, informando e oferecendo dicas para melhorar a eficiência do usuário durante o jogo.

O conhecimento torna tudo mais simples, melhora a eficiência, facilita o processo de reconhecimento e assimilação - essa é a maior contribuição da instrução. No entanto, alguns usuários poderiam considerar o próprio processo de instrução uma perda de tempo. Para evitar isso, os jogos digitais desenvolveram várias estratégias, desde a simples interrupção desse processo até a aproximação do jogo em si. Ou seja, a instrução pode ter uma fase específica que permite ao usuário se familiarizar com os elementos e se divertir. Os artefatos portáteis tem ainda a vantagem dos controles gestuais, que são os comandos naturais, que facilitam o processo de aprendizagem.

No processo de percepção, reconhecer as qualidades visuais da informação permite identificar as funções. No esforço de gerar contrastes entre os elementos pode-se optar pela redundância (verbal, pictórica e esquemática), embora este fato possa gerar uma complexidade visual.

Neste sentido, como resultado da pesquisa, pode-se relacionar os princípios às funções interativas. Da observação foram listados os princípios mais proeminentes. Eis o que foi encontrado:

- Estrutura informativa minimalista - atividades relacionadas ao processo de comunicação interativa "menu". Quando visíveis, devem ser apresentadas em estruturas simples, em uma ordem baseada nas expectativas dos usuários, de rápido e fácil acesso e percepção, excluindo informações irrelevantes ou raramente utilizadas.

- Redundância da informação - atividades relacionadas apenas à função de navegação. A redundância da informação é positiva para essas funções, pois é necessária ao processo cognitivo. Ocorre pelo uso de mais de um tipo de elemento gráfico.

- Contiguidade espacial-temporal - atividades relacionadas à função de instrução. Nesse princípio, os elementos gráficos da instrução devem estar próximos do ambiente do jogo, com associação simultânea dos elementos ao momento correspondente ao jogo.

- Redução da sobrecarga visual - atividades relacionadas à função de instrução e aos processos comunicativos feedback e "controle". É a relação entre a memória e a visibilidade. $\mathrm{O}$ usuário não deve se sobrecarregar com 
elementos visuais que compõem o sistema da interface, principalmente quando está nas atividades relativas ao jogo em si.

- Modalidade verbal - atividades relacionadas ao processo de comunicação interativa "menu". Deve-se priorizar o elemento gráfico verbal visto que estes são elementos visuais de imediata compreensão.

- Visibilidade do estado do sistema - atividades relacionadas ao processo de comunicação interativa feedback. O sistema interativo deve sempre manter o usuário informado, em todos os momentos.

- Mapeamento - atividades relacionadas ao processo de comunicação interativa "controle". Referem-se à linguagem adequada e à forma que os usuários percebem e determinam as relações entre intenções e ações possíveis. Em dispositivos portáteis há uma tendência em controles gestuais.

\section{CONCLUSÃO}

Neste artigo foi apresentado o resultado de pesquisa de análise de elementos gráficos em jogos digitais em dispositivos portáteis. Para tal foi apresentado a estrutura de análise com as funções interativas com o posterior detalhamento da pesquisa.

Com a observação e a análise pode-se constatar que cada função emprega elementos gráficos e estratégias peculiares de estruturação da informação. Pelo fato da ferramenta de apoio estar estruturada de acordo com as funções e estratégias, foi possível verificar a associação entre funções e princípios. Além disso, a configuração da ferramenta de apoio permite comparar os elementos gráficos por funções e estipular quantos tipos de elementos gráficos há em todas as estratégias. Desta forma, pode-se, não só verificar os elementos e estratégias mais recorrentes como cruzar os dados e refletir sobre outros aspectos tais como os processos cognitivos, eficiência de uso, entre outros.

Os princípios relacionados foram: Estrutura Informativa Minimalista, Redundância da Informação, Contiguidade Espacial-Temporal, Redução da Sobrecarga Visual, Modalidade Verbal, Visibilidade do Estado do Sistema e Mapeamento. Da observação e análise foi possível constatar que:

- A Navegação está associada ao princípio de Redundância da Informação, pois é a que mais emprega diferentes tipos de elementos gráficos.

- A Instrução está relacionada aos princípios da contiguidade espacialtemporal e a redução da sobrecarga visual. O princípio Contiguidade Espacial-Temporal relaciona-se ao fato da instrução está próxima aos elementos de manipulação e ao ambiente do jogo. A Redução da Sobrecarga Visual se deve ao fato de que pode ser empregado apenas um elemento gráfico e ainda ter eficácia no processo de interação comunicativa.

- O Menu está associado a dois princípios. A Estrutura Informativa Minimalista refere-se ao princípio de formas simples para organizar as informações e a Modalidade Verbal refere-se ao princípio que a linguagem verbal é a mais eficiente no processo de comunicação.

- O Feedback está veiculado a três princípios. Redução da sobrecarga visual a qual confere à função o uso mínimo de elementos gráficos. A 
Visibilidade do Estado do Sistema especifica que a informação deve estar presente em vários momentos e ambientes do sistema.

- O Controle está relacionado a dois princípios. A Redução da Sobrecarga Visual, devido à estratégia gestual, a qual não emprega elementos visuais. Mapeamento é a forma como os usuários controlam e manipulam os componentes do sistema interativo.

Essa metodologia aqui apresentada pode contribuir para trabalhos futuros tanto em jogos digitais para dispositivos portáteis, quanto pode ser adaptada para outros tipos de sistemas interativos. As observações e indicações que ela pode realizar contribuem para melhoria de interfaces por meio das incidências críticas e pelas indicações dos princípios relacionadas ao dispositivo, atividade e sistema. Com o cruzamento de dados bem como o levantamento bibliográfico pode-se discutir e estabelecer teorias acerca dos objetos de estudo.

Outra contribuição pertinente a essa metodologia refere-se à forma com que esse método propõe para comparar sistemas já existentes, permitindo fornecer dados e informações relevantes para o novo projeto de artefatos interativos, constituindo assim, um ponto inicial para aprofundamento de temas, permitindo construir novos questionamentos como:

- Qual a estratégia de estruturação mais eficiente?

- Qual elemento gráfico mais adequado para memorizar, instruir e manipular?

- As relações estabelecidas entre funções e princípios se mantem em outros sistemas?

Conclui-se que é fundamental conhecer em qual momento um princípio é mais relevante e como a informação se estrutura em uma dada função. No entanto são necessários outros estudos para definir todas as questões nela apresentada, ainda mais em um cenário em constante transformação, como são os artefatos digitais. Por fim, vale ressaltar a importância do desenvolvimento de um método de análise. Apesar de ser proposta uma ferramenta de apoio para observação e análise de jogos, percebe-se que é possível ampliar ainda mais a amostra a fim de garantir a eficiência da análise.

\section{REFERÊNCIAS}

BARBOSA, Simone Diniz Junqueira; SILVA, Bruno Santana da. Interação humanocomputador. Rio de Janeiro: Elsevier, 2010.

CYBIS, Walter. Ergonomia e usabilidade: conceitos, métodos e aplicações. São Paulo: Novatec, 2010.

MAEDA, John. As leis da simplicidade: design, tecnologia, negócios, vida. São Paulo: Novo Conceito, 2007.

NEIL, Thereza. Padrões de design para aplicativos móveis. São Paulo: Novatec, 2012.

PADOVANI, S.; MOURA, D.; Navegação em hipermídia. Rio de Janeiro: Moderna. 2008. PETTERSSON, Rune. Information design: an introduction. Philadelphia: John Benjamins Publishing Company, 2002.

PRESSMAN, R. S. Engenharia de software. São Paulo: Markron Books, 1995.

ROGERS, Yvonne; HELEN, Sharp; PREECE, Jennifer. Design de interação: além da interação humano-computador. 3. ed. Porto Alegre: Bookman, 2013.

XAVIER, Guilherme. Cultura visual nos jogos eletrônicos. Teresópolis: Nova Ideia, 2010. 